\title{
An Agonistic Approach to Technological Conflict
}

\author{
Eugen Octav Popa ${ }^{1}$ (1) $\cdot$ Vincent Blok ${ }^{1} \cdot$ Renate Wesselink ${ }^{2}$
}

Received: 20 July 2020 / Accepted: 23 September 2020 / Published online: 8 October 2020

(C) The Author(s) 2020

\begin{abstract}
Traditional approaches to conflict are oriented towards establishing (or re-establishing) consensus, either in the form of a resolution of the conflict or in the form of an 'agree-todisagree' standstill between the stakeholders. In this paper, we criticize these traditional approaches, each for specific reasons, and we propose and develop the agonistic approach to conflict. Based on Chantal Mouffe's agonistic democratic theory, the agonistic approach to conflict is more welcoming of dissensus, replacing discussion stoppers with discussion starters and replacing standstills with contestation. We illustrate such replacements and develop this approach, we analyse technological conflicts in a concrete R\&D setting: the global hydrogen economy. From this context, we focus on the conflict between the proponents of blue hydrogen (drawn from fossil fuels) and those of green hydrogen (created through electrolysis). We conclude by highlighting the advantage of the agonistic approach but also drawing attention to its own specific risk, namely, antagonism.
\end{abstract}

Keywords Conflict · Agonism · Consensus · Hydrogen economy · Chantal Mouffe

\section{Introduction}

Technological conflict, by which we mean explicit or implicit disagreement between stakeholders regarding the development or use of a certain technology, is ubiquitous in

\author{
Eugen Octav Popa \\ eugen.popa@wur.nl \\ Vincent Blok \\ vincent.blok@wur.nl \\ Renate Wesselink \\ renate.wesselink@wur.nl
}

1 Department of Communication, Philosophy and Technology, Wageningen University and Research, Wageningen, Netherlands

2 Department of Education and Learning Sciences, Wageningen University and Research, Wageningen, Netherlands 
the history of technology (Frey 2019). Whether the conflict occurs between the proponents and the opponents of a technology, as in the case of public and political resistance to new designs, between the proponents of a technology and the proponents of an alternative technology, as in the case of competing designs, disagreement seems to accompany (technological) innovation in a most natural way. The question of how to deal with technological conflict is therefore of chief concern to the stakeholders involved.

Recent calls for responsible research and innovation might make the question of how to deal with conflict even more urgent. For responsible research and innovation implies the participation of stakeholders from different sectors such as academia, industry, civil society and policy (Stilgoe et al. 2013; van den Hoven et al. 2014). These stakeholders will bring different worldviews and different 'institutional logics' to the proverbial round table (Thornton et al. 2012). Diversity might thus breed even more (or more intense) conflicts. In the case of technological hazards scholars speak of the 'problem of many hands' (Poel et al. 2015), i.e. the inability to always pinpoint who is responsible for risk in complex situations with many actors. But here we might need to speak of the 'problem of many heads', i.e. the near inevitability of conflict in complex situations involving stakeholders who see and think about technology differently. It is no surprise then that technological conflict has become a cross-cutting theme that interests both scholars working on responsibility in innovation (e.g. Cuppen et al. 2019; Ligtvoet et al. 2016; Dignum et al. 2016; Swierstra and Rip 2007) as well as philosophers and historians of technology in general (e.g. Glorioso 2015; Jones 2019) or specific technologies (Markusson et al. 2012).

Currently, there is a surprising uniformity of approaches in both understanding and managing conflict (Blok 2019; Cuppen 2012; Hård 1993). Practitioners and theorists generally favour a conciliatory approach in which differences between parties are reduced through interaction. Consensus and alignment of views are deemed necessary for effective partnership (Blok 2019). The general direction of both scholarship and practice is that the prototypical proponent of a technology (say Shell) and the prototypical opponent (say Greenpeace) should try to find each other in the middle in order to be able to collaborate. In the process, some identity loss is inevitable as the stakeholders get closer to each other, but this is all for a good cause: leaving behind their most strict demands and convictions, what is lost in identity is gained in collaborative capacity.

More recent studies have argued that a conciliatory approach is not always possible or desirable and have proposed instead a constructive approach (Ligtvoet et al. 2016; Cuppen 2012; Hård 1993). The constructive approach is more inclined to build on conflict, instead of trying to resolve it away. The constructive approach is also seeking to put to good use the stakeholder diversity resulting from cross-sectoral collaboration. In this view, conflict is not a problem to be solved but a much-needed trigger for learning about the values, institutional ties, and worldview of others. The constructive approach still shares with the previous approach the idea that conflict needs to be properly regimented, for example, by only allowing some forms of ('good') conflict and avoiding others. Yet importantly, the constructive approach differs from the conciliatory one in that they do not push for a reduction of values and identities for the purpose of friendly collaboration. Rather, the constructive approach seeks to help stakeholders gain 'an improved understanding of the diversity of perspectives on the 
problem and its potential solutions' (Cuppen 2012, p. 26). In the constructive view, Shell and Greenpeace ought to listen to each other and take due note of their different worldviews without necessarily trying to aim for consensus. The conciliatory and the constructive approaches to conflict have their particular merits, and they have certainly proven their mettle in the past. Yet, the aforementioned context of responsible research and innovation brings forth a peculiar situation, that of stakeholders wanting to collaborate while holding fundamentally different views on how to move forward, views that are not only incompatible in practice but also in principle. In the context of such 'unbridgeable differences' (Blok 2019), both the applicability and the efficiency of the conciliatory and constructive approaches can become questionable. For example, in the conciliatory approach, the consensus can be 'rigged' by stakeholders who recourse to immunization strategies and knock-down arguments that pull the consensus towards their preferred outcome. Similarly, taking a constructive approach, stakeholders can seek to reach an agree-to-disagree standstill through which they indeed learn about each other but have not learned from each other and have not been responsive to what they have learned.

In this paper, we wish to bring these risks more clearly to the fore and present a complementary third approach: an agonistic approach to conflict in innovation. The agonistic approach borrows its name from agonistic democratic theory, primarily the works of Chantal Mouffe (Mouffe 1999; Mouffe 2000), and builds on recent studies that apply these insights from political science to science and technology studies (STS). With the present analysis, we seek to further this cross-fertilization between political sciences and STS by illustrating how an agonistic approach can be employed to tackle the risks mentioned above and thus extend our methodological pallet of dealing with conflict in inclusive innovation systems. Agonism, we will argue, can provide a novel and effective third approach to conflict in the context of diverse stakeholders meeting on the global arena of technology development.

In Sect. 2, we review the past approaches to conflict mentioned above- the conciliatory and the constructive approach. We will discuss their added value and their risks. In Sect. 3, we then introduce the agonistic approach to conflict discussing its philosophical roots and its practical implications. In Sect. 4, we analyse and further explore the claims made in the previous two sections by building on a case study: innovation in the hydrogen community and the 'blue/green' discussion. We conclude in Sect. 5 with a review of the three approaches to conflict and suggestions for further research.

\section{Past Approaches to Dealing with Conflict}

\subsection{The Conciliatory Approach}

The conciliatory approach to conflict is dominated by a view of conflict 'as a dreaded disease or as a disruptive, even deviant activity' (Putnam 1994, p. 284). With such a characterization of conflict as a starting point, parties are expected to want to resolve conflicts and scholars compete to find the most efficient way to resolve conflict fast and efficiently (Sandole et al. 2008; Deutsch et al. 2011; Bercovitch et al. 2008; Jeong 2009; Wall Jr and Callister 1995; Poitras and Le Tareau 2008; Avgar 2016). At the same time, some researchers draw a more positive image of conflict, admitting that 
under some circumstances, conflict can have beneficial effects such as re-establishing power balances, liberating individuals from institutional constraints or increased ingroup cohesion (Deutsch 1994; Putnam 1994; Elgoibar et al. 2016; Jehn et al. 2012). It would seem that in optimal dosages, conflict can have a positive effect on a team by increasing the performance, specifically its creative capacity and innovativeness, and by pulling its members out of their comfort zone. However, even in the strain of research that sees conflict as a potentially positive phenomenon, the focus remains on resolving conflict before it derails towards some of its unproductive variants. This tendency to aim at consensus or congruence is also observable in the literature on responsible innovation, whether RRI or related frameworks (for overviews see Blok and Lemmens 2015; Blok 2019; Cuppen 2012). The in-built assumption in these areas is that value-alignment between stakeholder groups is vital for collaboration and that participatory methods, welcoming of conflict and deliberation as they may be, must deliver this alignment. With this as a starting point, methods have been proposed to align stakeholders' perceptions (or values) and to help them 'reconcile their divergent value creation frames in order to co-construct social value' (Le Ber and Branzei 2010).

The focus on conflict resolution is a very valuable default position when approaching conflict. The conciliatory literature is based on the undeniable evidence that conflict can affect trust among members of a group (Balliet and Van Lange 2013) and that unresolved conflict can slow down a team, have negative psychological and physiological effects on the ones involved (De Dreu 2008). That resolution is a preferred response to conflict in organizations should therefore not surprise us. However, in the context of responsible innovation and particularly where stakeholders perceive their differences as being irreconcilable, the exclusive orientation towards resolution is questionable. A series of recent studies have taken a closer look at this assumption and have concluded that the orientation towards resolution is a way of reducing pluralism of views and, as such, a way of circumventing the many benefits that can result from a pluralist innovation environment (Ligtvoet et al. 2016; Cuppen 2012; Brand et al. 2020; Blok 2019; Cuppen et al. 2019).

Aside from not reaping the benefits of pluralism, the conciliatory approach also presents a specific risk. Scholarship on public engagement has noted that a focus on argumentation- and negotiation-based interactions tends to favour those that already have increased negotiation power and access to what they perceive as knock-down arguments (Stilgoe et al. 2014; Selin et al. 2017). If 'win the other party over' is the name of the game, then the game is played by showing that your conclusions are derived through valid reasoning from true premises. Not only is this practice reinforcing existing power structures that favour those with plenty of access to argumentative means and thus stifles engagement (Irwin et al. 2012), but it creates as we will see the temptation of delivering a decisive blow, an argument that ends the discussion in favour of its proponent. Such discussion stoppers are not irrational or unfair, they are simply the agents' rational response to a problem that is laid before them in rationalistic (gametheoretical) terms, viz. do you prefer resolving the conflict in your favour now or would you rather have the other party continue with their input? When playing the game of convincing, it is a matter of basic rational strategy to seek to win (van Eemeren 2010). In such a context, discussion stoppers or 'immunization strategies' (Blok 2019), that is, strategies that block certain claims from receiving critique, constitute a tempting fast lane towards a favourable resolution. 


\subsection{The Constructive Approach}

In a constructive approach, scholars see conflict as a necessary, if not always altogether pleasing, pathway towards learning about the others and their views (Cuppen et al. 2019; Ligtvoet et al. 2016; Cuppen 2012; Hård 1993). The approach tends to highlight the role of diversity which, through conflict, is seen as a kind of catalyst for learning. The constructive approach does not shy away from ruffling a few feathers if the process leads to an 'open exploration of divergent perspectives' (Cuppen 2012, p. 26). With this as a starting point and by integrating insights from other participatory methods that share this openness towards conflict (e.g. van de Kerkhof 2006), Cuppen proposes a dialogue methodology for enhancing learning based on diversity. While some limitations on the 'cognitive distance' between stakeholders are advised, pluralism of ideas and perspectives is encouraged. Furthermore, the stakeholders involved in such interactions do not necessarily aim to resolve their differences of opinion - another crucial point of difference between this approach and the previous one. The dialogue is 'open ended, in the sense that it does not necessarily result in one consensus policy option or strategy' (Cuppen 2012, p. 26). Rather, the argumentative interactions 'should stimulate participants to engage in a process of reflection' which leads to 'a better understanding of other ideas and the relation to their own ideas' (Cuppen 2012, p. 33).

There is much to be discussed on the details of concrete constructive approaches. For instance, the measurement of the stakeholders' learning after they have participated in this constructive form of conflict is not operationalized or measured precisely. But here we would like to consider the approach in its general traits. In our view, the attempt to see conflict as a form of collaboration - the continuation of collaboration by other means, so to speak - is a laudable attempt to portray conflict as valuable. Also, with its focus on the learning process, the constructive approach places due focus on stakeholder identities and the rationality claim made by sectoral and organizational worldviews. Unlike the conciliatory approach, which ultimately encourages consensus and the melting of views into one another with all the mentioned drawbacks, the constructive approach is problem restructuring rather than problem solving. Because of such features, the constructive approach appears as a promising alternative to the traditional conciliatory one.

However, we would like to signal several risks. One important risk of the constructive approach remains that learning in itself does not presuppose or demand any action, any effect of the learning process into practice. The absorption of new world-views might remain a mere intellectual exercise. True, stakeholders absorb each other's narratives and are subsequently capable of reproducing it or comparing it to their own narrative, but this form of passive learning is not afterwards connected in any evident way to behaviour (change). Learning through such conflict-friendly verbal interactions allows for the possibility of returning to business as usual despite what has been learned. Specifically, when 'the aim of stakeholder dialogue as a problem structuring is thus to learn about a problem and its solutions' and when learning means 'an improved understanding of the diversity of perspectives on the problem and its potential solutions' (Cuppen 2012, p. 26), these outcomes do not necessarily imply that the stakeholders involved act in any way differently because of what they learn. In the example of biomass, which Cuppen uses in her study, different perspectives on biomass were first identified, then articulated and discussed by the selected individuals, yet the 
resulting visions, despite their undoubted learning effect, constituted the end-point of the dialogue (p. 40).

The reaching of such agree-to-disagree situations seems to preclude or in any case ignore the idea of responsiveness to a conflicting demand, an idea that has been put forward in literature of responsible innovation (Owen et al. 2013), ethics of innovation (Blok 2019) and ethics of technology (Hansson 2017). It is generally assumed that modifying one's behaviour because of the Other's ethical demands is an essential component of responsible innovation, for otherwise being responsible would dissolve into merely having an encyclopaedic knowledge of others. The risk associated with this approach is, as we will show, that parties actively seek and enjoy a standstill by comfortably avoiding direct conflict while admitting the other stakeholders' equally acceptable views. In our imaginary example, the constructive approach would have Shell and Greenpeace interact in a conflictual but friendly manner, they would listen to each other and learn about each other's worldview, and everybody will go home satisfied that instructive exchanges have taken place. Beneficial as this may be, we would like to draw attention to the risk that such exchanges have no actual effect in practice. Two fundamentally different worldviews can meet and politely tango for several hours without all this resulting in any kind of change in practice.

\section{An Agonistic Approach to Conflict}

In this section, we want to introduce and explain an agonistic approach to dealing with conflict in innovation. Agonism, etymologically referring to competition, is in its most basic form an assumption about society: the assumption that conflict is fundamental for society since it constitutes the process through which group and individual identities are constituted (Mouffe 2005; Erman 2009). Agonistic thinkers such as Chantal Mouffe and James Tully stress the importance of fostering agonism as an alternative to the traditional liberal tradition in which order is ultimately dependent on a 'rational consensus' on both fundamental matters and matters of detail and practice (Mouffe 2000 , p. 7). Yet, in the presence of irreconcilable differences, which they assume to exist on even the most fundamental questions of value, consensus ends up being nothing but 'a temporary result of a provisional hegemony, as a stabilization of power, and that it always entails some form of exclusion' (2007: 104). With pluralism as the driving force of society, the 'established view' entails the negation or at least diminishing of other views. Although the details of this agonistic process are the subject to much discussion in political philosophy (see a recent overview Paxton, 2020), the translation of agonistic principles to responsible innovation results in a novel take on stakeholder engagement (Blok 2019). From an agonistic perspective, conflict is to be sought and agonistic respect must take the form of being responsive to the other party's ethical demand. Concretely, this will mean that Greenpeace and Shell must seek conflict with each other not because of the possibility of an ideal agreement, or a comfortable 'agree-to-disagree' standstill, but rather in order to continually restate and reinterpret each other's ethical demands and translate these demands into responsive behaviour. A resolution or a standstill, in agonistic thinking at least, would be bad news for both organizations. 
It is worth stressing that agonism is not just another refrain of the song 'one should always be open to criticism'. Mouffe for example looks at prominent liberal thinkers such as Rawls and Habermas and notices that, in their attempt to unify liberal thinking and democratic participation, they all assume one way or another that values are to be discussed and negotiated based on neutral 'rational' procedures and models (Mouffe 2000 , p. 89-94). The fear that the marriage between liberalism and democracy would collapse in the absence of such an Archimedean point is an inertial remnant of Enlightenment and we should be courageous in accepting pluralism of values and interpretations of values:

Not only can [the search for rational procedures and models] not succeed, but moreover it leads to putting undue constraints on the political debate. Such a search should be recognized for what it really is, another attempt at insulating politics from the effects of the pluralism of value, this time by trying to fix once and for all the meaning and hierarchy of the central liberal-democratic values. Democratic theory should renounce those forms of escapism and face the challenge that the recognition of the pluralism of values entails (Mouffe 2000, p. 93).

Of course, pluralism does not entail an anything-goes attitude where no constraints are placed on stakeholder interaction. Rather, the constraints that are deemed necessary for a fruitful discussion, for example constraints regarding stakeholder selection, discussion setting, turn-taking, etc. are to be recognized for what they are: the expression of a temporary, precarious and challengeable modus vivendi rather than a code of conduct that must be derived from rationality and morality.

In the context of responsible innovation, the agonistic approach will seek to multiply and foster social practices of conflict, practices where multiple values and value interpretations can compete. The backdrop and organizing principle of such practices is not a 'neutral' ideal of rationality or a shared goal, but rather the ethico-political bonds of citizenship. The innovation community must thus be organized not as a universitas - an association of people with an established (universal or common) goal and values that select those who seek membership — but as a societas - an association without an established ideal or a shared goal but with a minimal agreement on practices of civility and competition and a common understanding that these rules are but a temporary modus vivendi (Oakeshott 1990). If the innovation community is seen as a societas, and if it is pushed towards this structure as agonistic scholars would have it, then the encounter between Greenpeace and Shell, to go back to this prototypical example one last time, should be precisely one that seeks to enhance existing competitive language games and discover new ones where the expression of irreconcilable values can thrive. It is as if, short of a universal game to decide whose will is to prevail, Greenpeace and Shell must engage in a wide variety of other imperfect games, some bound to favour Greenpeace, others bound to favour Shell, and they do so under the recognition that only participation in these games the identity of Greenpeace and Shell are constituted, i.e. makes them the way they are (Blok 2014).

Compared to the previous approaches, the agonistic approach is much closer to the constructive approach than the conciliatory one. The difference between the agonistic approach and the conciliatory one lies in the emphasis that the agonistic approach places on the beneficial power of conflict and the continued efforts to sustain conflict 
and identities rather than resolve or settle it. Less obvious is the difference between the agonistic approach and the constructive one, perhaps because both emphasize the potential benefits of conflicts. This similarity notwithstanding, the two are different in the preferred responses they seek from the conflicting parties: in a constructive approach, the preferred response to conflict is a cognitive one; in an agonistic approach, the preferred response is an ethical one (Blok 2019). The cognitive response is that of trying to understand the other stakeholders that participate in the conflict - the reasons that support their claims and more generally the worldview from which these claims arise. Laudable as this endpoint might be, the agonistic approach seeks to go one step further beyond understanding towards responsive behaviour and action not in regard of the conflict but the stakeholders' value and identity. For the ethical response is that of taking pluralism seriously and seek to respond and adapt their own identity because of the other party's ethical demands (Blok 2019, p. 253). Stakeholders thus struggle to find out how to achieve what is always at face value very difficult or even impossible: how to respond in such a way that the perspective of others is not cast aside as mere irrationality but as a legitimate viewpoint with which a modus vivendi must be found (Mouffe 2000, p. 23). Indeed, it is precisely in a situation where such an ethical response to others cannot be fully justified by appeal to reason that its ethical character is revealed.

Since we have highlighted the risks in the past approaches - immunization in the case of the conciliatory approach and standstills in the case of the constructive approach - we should highlight that the agonistic approach is not without its risks. One such risk is pure (or proper) antagonism. Chantal Mouffe distinguishes pure antagonism as follows:

I propose to distinguish between two forms of antagonism: antagonism proper which takes place between enemies, that is, persons who have no common symbolic space - and what I call 'agonism', which is a different mode of manifestation of antagonism because it involves a relation not between enemies but between 'adversaries'. Adversaries being defined in a paradoxical way as 'friendly enemies'. That is, persons who are friends because they share a common symbolic space but also enemies because they want to organize this common symbolic space in a different way (Mouffe 2000, p. 13)

Mouffe concludes later in the same work that 'the aim of democratic politics is to transform antagonism into agonism' (ibid., 103). For the present purposes, we note therefore the risk that agonism can turn into antagonism. In this sense, glorifying conflict can be a risky business without simultaneously promoting responsiveness as the preferred ethical response. Responsiveness to the other stakeholders' claim, referred to in agonistic theory as 'agonistic respect', is what distinguishes agonism from mere argumentativeness or belligerency. Responsiveness is not agreeing but rather the integration of external values into the innovation processes and its resulting products (Owen et al. 2012). This integration does not need a full-blown agreement or even a unified understanding of the products in question, but it needs piecemeal changes that result from a constant dialogue (Friedman 1997). It is thus in this constant dialogue of science and technology co-creation that responsiveness occurs and the risk of antagonism is minimized. 
In the next section, we will further flesh out the meaning and consequences of an agonistic approach to conflicts. We do so by looking at stakeholder communication in a specific innovation context: the currently uprising of global hydrogen economy. By means of this case study we seek to apply the hitherto theoretical claims we have made and to show how, in practice, agonism can form a solution to the risks created by the other two approaches.

\section{Case Study: an Agonistic Approach to Conflicts in the Hydrogen Economy}

\subsection{The 'coal of the future'}

Hydrogen is an invisible, tasteless, colourless, gas that constitutes the most abundant chemical element in the universe. Hydrogen is highly reactive, which means that it bonds quickly with other elements - such as oxygen, to form water-which makes it a key element in a variety of industrial processes, yet it is by definition a non-polluting gas (Hoffmann 2012). It is facts like these that probably set off Jules Verne's imagination in a passage about the future of hydrogen from Mysterious Island (1875).

Water [...] decomposed into its primary elements, and decomposed doubtless by electricity, which will then become a powerful and manageable force. [...] Yes, my friends, I believe that water will one day be employed as fuel, that hydrogen and oxygen which constitute it, used singly or together, will furnish an inexhaustible source of heat and light, of an intensity of which coal is not capable.

This passage is not merely a figment of Verne's imagination. In the early nineteenth century, the application of electric current to chemicals for the purpose of decomposing them into their primary elements, a process known as electrolysis, was an immensely popular experimental setup among chemists (De Levie 1999; Partington and McKie 1939; Snelders 1979). The electrolysis of water, by which water is split into hydrogen and oxygen, has been variously experimented before this time, but it was not until the year 1800 that Volta's battery provided a stable electric current that a number of practical problems had been solved and 'water splitting' was controlled and understood (De Levie 1999). History marks the experiments of William Nicholson and Anthony Carlisle, carried out around the year 1800, as the birthplace of water electrolysis (Kreuter and Hofmann 1998).

Hydrogen is of primary interest in refining industries and the production of fertilizers as well as combustion at extremely high temperatures. Due to an increased demand for cheap hydrogen in heavy industries, hydrogen producers gradually abandoned water electrolysis and turned to fossil fuels (LeValley et al. 2014). Hydrogen can be produced very efficiently — and thus at a relatively low cost— by using natural gas or other fossil fuels as feedstock. It was not until the end of the twentieth century, triggered by the oil crisis in the 1970s and the increased policy push for the decarbonization of industry, that R\&D turned back to water electrolysis, rerailing to Verne's timeline as it were. In the 1990 s, the science of the materials used in electrolysis were not much different than four decades earlier, 'this lack of consistent development' being attributable to the 
producers' preference of the cheap and reliable use of fossil fuels for the bulk production of hydrogen (Carmo et al. 2013). The lock-in of fossil-fuel technologies for hydrogen production is still visible today: the hydrogen demand 'is almost entirely supplied from natural gas and coal' and this production is 'responsible for annual $\mathrm{CO}_{2}$ emissions equivalent to those of Indonesia and the United Kingdom combined' (IEA 2019, p. 14).

As a result of these separate developments, the following terminology gradually emerged:

- 'grey hydrogen' referred to hydrogen produced from fossil fuels

- 'blue hydrogen' referred to hydrogen produced from fossil fuels with carbon capture and storage

- 'green hydrogen' referred to hydrogen produced from renewable sources

Importantly, the status of hydrogen in the energy transition is ambivalent. On the one hand, the use of fossil fuels and the emission of $\mathrm{CO}_{2}$ make hydrogen an antihero; on the other hand, the environmental gains that could result from cleaning this production, as well as hydrogen's use as an energy carrier, place hydrogen as one of the main heroes in the energy transition. As early as 1972, the term 'hydrogen economy' was coined envisioning an economy that is fully dependent on hydrogen from households to air travel and heavy industry (Bockris and Appleby 1972). Some delay notwithstanding, Verne's prophecy is starting to materialize, but the hydrogen economy is not without its hurdles.

\subsection{The Colour Conflict in Hydrogen R\&D}

To illustrate the application of an agonistic approach, we will focus on one aspect of the hydrogen economy and place it in a concrete socio-economical context: the choice of technology for hydrogen production. We will refer to this as the 'colour conflict' following the aforementioned tradition in the energy sector to use colour labels for specific technologies. The colour conflict forms a good case in point for studying agonism for several reasons. First, it is a conflict on value judgements. Despite some technical terms appearing sporadically in these discussions, the conflict rests on value judgements on what is wise or strategic to do as a matter of energy policy (production, distribution and consumption of energy). The choice of hydrogen technology is thus, at least in part, a choice in how society wishes to approach the decarbonization of industry and what values stakeholders prioritize in carrying out this transition. The parties cannot therefore calculate their way out of the conflict. Second, the colours are mutually exclusive: one cannot easily (e.g. daily or monthly) switch from production of blue hydrogen to green hydrogen or vice versa. The commitments are therefore momentous and there is therefore little chance of a middle-way consensus. Third, with the exception of grey hydrogen, which everybody dislikes, none of the 'good' colours are wholly bad or wholly good. There are, as we will see, plenty of arguments on both sides to keep all options alive and hence the colour conflict slowly simmering. Let us briefly review the cases brought on both sides. 
The advantages of blue hydrogen are primarily economic and technical: blue hydrogen is much cheaper than green hydrogen and the technology, while 'not often used', still 'has a high technology readiness level (TRL)' (Hers et al. 2018, p. 32). The high TRL meaning that the technology is almost ready to be implemented on a large scale wherever the necessary fossil resources are available. Another economic advantage of blue hydrogen is that, given its availability on short term, investing in blue hydrogen now can develop the market and infrastructure for green hydrogen later paving the way and accelerating the transition towards carbon neutral hydrogen production (ibid., p. 42). The urgency of undertaking to clean the industry sooner rather than later is often quoted as a reason why blue hydrogen might in fact not be just a 'satisfactory' temporary cleanup. The advantages of green hydrogen, in contrast, are primarily environmental: because electrolysis can work with renewables, meaning that resource depletion is avoided, and it can produce hydrogen with no $\mathrm{CO}_{2}$ emissions. Green hydrogen is heralded as 'clean and safe energy carrier that can be used as a fuel in transportation and electricity production or as an industrial feedstock' (Northern Netherlands Innovation Board 2018). Additionally, green hydrogen produces hydrogen of high purity and the electrolysis plant is a well-known construction with relatively low maintenance needs (H2Future 2020). The arguments for green hydrogen are thus primarily ecological and practical.

In the case of blue hydrogen, the technology of CCS forms an additional barrier. This technology is needed to turn the grey hydrogen in to blue one by capturing the resulting $\mathrm{CO}_{2}$ and thus preventing its emission into atmosphere. However, CCS comes with its own socio-ethical background of safety risks (Wennersten et al. 2015) and social resistance to these risks (L'Orange Seigo et al. 2014). Additionally, for countries that do not have large in house fossil fuels resources, the price of the main resource is projected to rise in the coming decades. Another cited disadvantage in the deployment of blue hydrogen is technology 'lock in', i.e. the 'blue' technology might end up being with us longer than we would like, whereas green hydrogen would be the preferred end result (International Energy Association 2020).

The persistence of the blue vs. green debates at the time when green hydrogen projects were launched can also be seen at a global scale. In Germany, for instance, the debate was made public as the 'blue vs. green dilemma' at the beginning of February 2020 when the Merkel government turned out to be divided on the blue vs. green matter: the minister of economics and energy confronting ministers of both science and environment on the issue (Radowitz 2020). Peter Altmaier, the ministry of Economic Affairs and Energy included blue hydrogen in the list of subsidized technologies arguing that blue hydrogen 'will also have to play a role, above all for economic reasons'; in response to this, Anja Karliczek, the German minister of Education and Research, said in an interview that 'the future belongs to green hydrogen alone' (Radowitz 2020, italics added). In addition, the discussions mentioned in the previous section-Syversen's defence of blue hydrogen in response to the EU Hydrogen Initiative which favours green hydrogen exclusively-were still very much on the public agenda, both in The Netherlands and worldwide (Gasterra 2019). 


\subsection{From Immunization to Vulnerability}

The risk of the conciliatory approach consists in the occurrence of immunization techniques. In the blue/green discussion, there is no shortage of strong statements that are presented as knock-down arguments that leave no room for continuation. Importantly, in illustrating these interactions we do not seek to evaluate the strength of these arguments or their persuasiveness. Nor we are claiming that the immunization strategy was effective, meaning that the immunized claims were indeed, as a result, seen as selfevident. Rather, we are merely noting the contributions that frame the discussion and the identity of the participants. Let us look at some examples.

In a February 2020 interview for the specialized UK magazine Recharge (Collins 2020), the chief executive of a UK-based electrolyzer manufacturer, Graham Cooley, presented his case as follows:

I'm worried that governments have been sold a pup with blue hydrogen and CCS. Not only is it more expensive than green hydrogen over the medium term, it does not help you with energy storage or assimilate more renewables on the network, and is not a net-zero [emission] technology.

To be 'sold a pup' in colloquial British means to be tricked into buying something that is of lesser value than you might have been made to believe. Cooley continues:

Blue hydrogen will always require a methane pipeline, which will always leak. The problem with blue hydrogen is that not only do you need a hydrogen pipeline, but you'll need a methane pipeline, then you'll need a $\mathrm{CO} 2$ pipeline. [...] And the only commercial application [for using captured CO2] is improving the efficiency of oil wells, which creates more CO2. So it's utter rubbish. [...] What I don't understand is how the oil \& gas industry has been able to convince governments [about the value of blue hydrogen]

The message in Cooley's contribution is not only that green hydrogen is in some ways better than blue hydrogen (a claim that might in that form find broad acceptance amongst stakeholders). Cooley's contribution is that stakeholders in the blue hydrogen community have nothing to show for themselves ('utter rubbish') and are hiding this by using tricks and stratagems ('sold a pup'). The case of blue hydrogen is so weak that their lobbying power towards governments remains a mystery. For Cooley, the case is closed. This contribution illustrates how in the public discussion on a certain technological path, doors can be closed by claiming incontrovertibly that the case has been won. It is not the weight of those reasons in absolute terms that makes them good illustrations of discussion stopping - it is their packaging as the final nail in the blue hydrogen coffin.

Discussion stoppers also appeared on the proponents of blue hydrogen. The following example will be taken from a blog post on the website of the International Association of Oil and Gas Producers (IOGP). The IOGP is an industry association that is committed, amongst other, to 'ensure that Europe remains open to oil and gas imports from other producing areas' (IOGP website). In a blog contribution about the compatibility of blue and green hydrogen, the author, Olav Aamlid Syversen, gives various reasons why the blue trajectory should be pursued and concludes: 
Importantly, this is not a game of playing a technological catch up with other regions of the world, but one of solidifying our leadership and reap long lasting jobs and growth opportunities. This is what should make blue hydrogen a no brainer for Europe. (italics added)

No brainers are not discussed, because it requires little or no mental effort to see who is right. Also, in a context where no other reasons for green hydrogen are mentioned, nor counter-arguments against blue hydrogen, the more ingenuous reader will be excused for thinking that green proponents only push their agenda because they are playing their 'technological catch up'.

In contrast with immunizers, we can now turn to some examples of vulnerability, where the criticizability and thus fallibility of choices is brought to the fore (TKI Nieuw Gas 2020). An illustrative example of conflict-fostering through the maintaining of the discussion can be found in a report on hydrogen published by TKI Nieuw Gas, a Dutch industry association in the field of energy. In presenting the hydrogen case, the document manages not to undertake any clear commitment for either blue hydrogen or green one, nor does it shy away from the discussion of alternatives. The authors mention the debate openly and serve some 'standard moves' that are made on both sides, for example:

Blue hydrogen can be used as a step towards green hydrogen. However, it is important to note that opinions differ around the use of blue hydrogen as a trailblazer for green hydrogen. Some stakeholders are of the opinion that green hydrogen is fast enough in order to scale up the necessary adjacent technologies and if necessary, large quantities of green hydrogen can be imported which makes blue hydrogen superfluous (TKI Nieuw Gas 2020, p. 27).

In the quote example, the proposal of blue hydrogen as a good means to ease the way towards green hydrogen is posited with significant conviction. Yet immediately afterwards, the matters are relativized, showing its vulnerability and allowing the discussion to continue living. Additionally, the problem of a low hanging fruit that comes with technological 'lock-in' and in fact the report ends with a series of questions such as the following: 'What is the role of blue hydrogen in relationship to green hydrogen, including aspects of timing/fasing, capacity, available stocks and cost perspectives? How does transition look like without the blue option? What is the role of grey [steam reforming without CCS] in this?' Questions are, of course, discussion starters par excellence but it is their suggestion regarding the status of the conflict that can also be highlighted: through questions, the discussion is maintained as open, ensuring that the parties keep looking for answers that either satisfy both parties or trigger new discussions.

\subsection{From Standstills ('Agree-to-Disagree') to Contestation}

A second risk identified in Sect. 2 in relation to the constructive approach was the appearance of standstills or 'agree-to-disagree' situations. In a standstill, all the parties involved maintain and defend their points of view without tackling what the other party has to say in the discussion. As a result, standpoints are defended and maintained- 
with or without immunization strategies - but there is no response to the other party's contributions, no interaction of moves and counter-moves, but still the intention to continue or have a constructive approach to the conflict. Methodologically speaking, standstills are more difficult to illustrate because their essence consists of what parties are not doing, namely they are not tackling the other party's counter-claims. It might thus be better to distinguish two variants: the full-blown standstills in which a stakeholder ignores both the other stakeholders' claims and their argumentation and a 'mild' standstill in which a stakeholder acknowledges the other stakeholders' claims but does not engage with their argumentation.

A standstill of the first variant can be found in the discourse around a project started in February 2020. The project, named NortH2 and initiated by a consortium of companies led by Gasunie (a Dutch state-owned gas operator), Groningen Seaports (operator and authority of various ports in Northern Netherlands) and Shell Nederland (Dutch-British oil and gas company) joined forces to build the country's biggest green hydrogen facility (Gasunie 2020). The project has been widely received with much support from various stakeholders and is seen, as one regional newspaper called it, a 'push in the right direction' (Geijp 2020). On the project website, Gasunie benefits of green hydrogen are reiterated: its use in the decarbonization of industry, its effects on air quality, the repurposing of the gas infrastructure and so on (Gasunie 2020). In an online video posted the same day as the announced kick-off of NortH2, the representative of the regional government spoke highly of the consortium's plans and refers to green hydrogen as 'the missing link'. 'The blue vs. green discussion is not mentioned in any of the communication outputs of these endeavours. In the Netherlands, at least, the green deal appeared to be sealed once and for all. This is then an example of the variant we called the 'full-blown' standstill where the discussion is simply left behind. To be sure, the project's choice to not stir up a hornet's nest in its starting phase is fully understandable from a practical point of view. Yet, the convention of starting a project with complete confidence about one's commitment (to green hydrogen) is after all just a convention and we should not assume that a more reflective, questioning attitude would necessarily have negative practical effects.

The second variant of the standstill, the one in which, unlike the previous variant, the other party's standpoint is acknowledged, yet their counter-claims are left aside, can be identified in the following example. Just several months before the NortH2 project, a project called H-Vision published its final report. The H-Vision consortium, which also included Shell and Gasunie, promoted blue hydrogen as a trailblazer for green hydrogen: the infrastructure developed now for blue hydrogen can be used later for green hydrogen and the market created now by blue hydrogen can be a landing board for green hydrogen later (H-Vision 2019). Unlike the previous example, where the blue colour was fully ignored, this report contains a section called 'Comparison with alternatives'. Yet, in this section and throughout the rest of the report, the authors do not engage with the known attacks stemming from the green community, such as the claims that that blue hydrogen is not emission-free, that it creates technological lock-in, maintains dependence to fossil fuels etc. Rather, the green hydrogen turns out to be not so green after all:

\footnotetext{
${ }^{1}$ Gasunie, Shell Nederland en Groningen Seaports presenteren NortH2 in Groningen: https://www.youtube. com/watch?v=pptY86ZVw1g
} 
It is important to note that green hydrogen is in competition with other decarbonization technologies for a renewable electricity energy supply, whereas blue hydrogen is not. This means that every megawatt of renewable power used for green hydrogen production cannot be utilized for other decarbonization applications, such as power-to-heat or E-mobility. Therefore, green hydrogen is only considered sustainable if produced from surplus and cheap renewable electricity. Currently, surpluses of green electricity do not exist - in the Netherlands, the share of renewable electricity is only $15 \%$ of the total electricity generation (H-Vision 2019, p. 77)

The conclusion is not spelled out explicitly but the reader is helped until just about the very last step: given that there is no surplus of green energy in the Netherlands and that green hydrogen is only sustainable if made by surplus green energy, it would follow that green hydrogen made with electricity that could be used directly ('for other decarbonization applications') is not sustainable. Similar arguments against green hydrogen are advanced later, such as the fact that green hydrogen cannot decarbonize refinery fuel gasses (since it is not made from gases to start with). From an agonistic point of view, the mild standstill is significantly more beneficial than the full-blown one- the other stance is at least recognized and some moves are made in the direction of fleshing out the conflict. However, from an agonistic point of view, the optimal form of contestation is that where 'agonistic respect' is exercised, meaning that not only the other party's standpoints are taken into discussion but also the other party's arguments against one's own standpoint.

In any one of the standstills illustrated above, whether the full-blown variant or the mild one, an agonistic approach would be an impetus for contestation. In contestation, parties seek to constantly refer back to the existing conflict, re-shaping that conflict with new contributions and in this way keeping the Others in the game. Contestation, in this regards, is nothing more than creating the textual and institutional space for responsiveness to the other's claims, critique, and values. Contestation in this case is not only possible, it has in fact been exercised outside the two mentioned projects. Thijs den Brink, a Dutch consultant and freelance writer on the energy transition, has been particularly active in the hydrogen discussion, all but refusing to accept the many standstills that were reached among stakeholders in the Netherlands. Two examples will illustrate the point. First, writing in a period where many embraced the idea of green hydrogen produced from surplus renewables, den Brink reacted with a piece in which he sought to show that green hydrogen from surplus green energy is not a viable business case. ${ }^{2}$ Importantly, the resulting text was not a quick dismissal of the idea of green hydrogen from surplus energy but rather a 'tough long-read' (in the author's own words) in which the topic is painstakingly considered on technical, economic and environmental matters. Even though his conclusion was written in no ambiguous terms, referring to the idea of green hydrogen from surplus energy as a 'worthless idea', the conclusion is arrived at through agonistic respect - that is, a thorough consideration of the claims made by his adversaries. The phenomenon of others supporting such a 'worthless idea' is not explained away on the basis of their partisanship or bias, but

\footnotetext{
${ }^{2}$ The article (in Dutch) can be found here: https:/www.wattisduurzaam.nl/16238/energie-beleid/waterstof-uitwaardeloze-groene-stroom-is-keihard-kansloos-2/
} 
rather explained through an in-depth analysis based on publicly available data, estimations and scenario-building. In a period where green appeared to be dominating the discussion, contestation appeared to be both possible and reasonable. A second example of contestation appears in a later piece by Den Brink, when the discussion was crystallized as we have seen into supporters of green and supporters of blue, den Brink reacted with a piece in which as much as 15 colours of hydrogen are distinguished (Den Brink 2020). ${ }^{3}$ These are then two examples of contestation that breach standstills and all but ignore signals that the discussion is resolved or settled. The effects of these contestations on the R\&D community are difficult to gauge, particularly since much interaction between stakeholders takes place behind closed doors, but the examples show that contestation was possible and in fact a highly fruitful approach in the same period where others took matters to be settled for good.

\section{Discussion}

Through our case study we have illustrated how the agonistic approach to conflict can result in a different critical perspective when analysing a debate. From this perspective, moves that tend to prevent conflict (immunization strategies) or ignore it (by creating various types of standstills) are sought to be replaced with moves that show vulnerability to counterclaim and openness to contestation.

In discussing these examples, we have abstracted away from the specific cultural context in which the interactions occurred. Placed in such a context, one might point out that stakeholders do not typically shy away from actual conflict because of some overconfident twist of phrase. These, one might say, are just tricks of the (writing) trade and the attempted prevention of conflict might not have been a successful prevention of conflict. We fully admit such possibility. Also, a more in-depth contextualization would need to place these discourses in their global context because the prevention or avoidance of conflict which we have identified might be the result of an attempt to enable consensus in view of increasing national competitiveness. In a globalized arena of industrial $\mathrm{R} \& \mathrm{D}$, the impetus for national unity and co-operation for increased competitiveness on the global market is particularly strong. For example, in March 2020, the Dutch Parliament solicited the Governmental to make The Netherlands the 'Hydrogen Gateway to Europe'. 4 Because of this, the tendency to reduce rather than breed conflict becomes not only a matter of organizational culture but a matter of patriotism. Seeing conflict as 'unduly burdening' the R\&D process is surely not a stretch, given that one of the

\footnotetext{
3 The 15 colours are defined as follows: 'grey hydrogen: steam methane reforming...', 'brown hydrogen: hydrogen from biomass or biogas...', 'blue hydrogen: grey hydrogen with $\mathrm{CO}_{2}$ storage...', 'silver blue hydrogen: cracking methane in hydrogen en solid carbon...', 'gold hydrogen: renewable hydrogen with $\mathrm{CO}_{2}$ storage...', 'bright green hydrogen: hydrogen from surplus green energy...', 'green hydrogen: electrolysis with renewable energy...', 'orange hydrogen: hydrogen from Dutch green energy...', 'purple hydrogen: hydrogen from nuclear energy...', 'pitchblack hydrogen: electrolysis with gas and coal energy...', 'red hydrogen: thermolysis of water', 'pink hydrogen: steam electrolysis', 'turqoise hydrogen: solar fuels'. The article (in Dutch) can be found here: https://www.wattisduurzaam.nl/17586/featured/duurzame-en-fossielewaterstof-in-alle-kleuren-van-de-regenboog/

${ }^{4}$ The Second Chamber Debate on hydrogen financing can be found here: http://2ekmr.nl/MeD
} 
practical consequence of entertained conflict can be a decrease in speed and mutual trust. The message of an agonistic pluralism might therefore fall on deaf ears in a context characterized by a common enemy and a culture in which success is associated with confidence and perseverance. An agonistic approach to conflict can function as a 'technology of humility' in Sheila Jasanoff's terms, a method of accommodating partiality, uncertainty and high complexity because 'humility instructs us to think harder about how to reframe problems so that their ethical dimensions are brought to light' (Jasanoff 2007). That said, an unequivocal 'glorification of dialogue' should be avoided as past studies have shown that such an attitude can distract from the actual problem at hand, a problem well known in public engagement literature (Selin et al. 2017; Stilgoe et al. 2014).

On a disciplinary level, we should point out that the cross-fertilization between agonism and innovation, or more generally between political philosophy and STS, is not without its dangers. ${ }^{5}$ The cross-fertilization has been undertaken recently by, e.g. Blok (2019) and with philosophical lenses by and Rey (2017). But the disciplinary dialogue should not be taken for granted. A first danger is that of misapplication of the theory of conflict engendered by agonism. The two contexts, politics and science, parliament and innovation system, are obviously different so we should be aware of important differences in the corresponding conflict situations. Simply put, the kinds of conflict stakeholders have about and around technology need not be the same as the conflicts that occur in politics over, e.g. spending, minorities, foreign policy, and public health. We should not assume that the agonism of Mouffe (or others) will apply mutatis mutandis to a situation where interaction is primarily led not by political ideals but by epistemic ideals of knowledge and non-epistemic ideals of scientific and perhaps economic success. A presupposition running through our account from the start is that individuals and institutions share a certain mutual idiom of what it means to disagree with others - what it means to not be fully aligned whether in your political or your innovation goals. It is this shared understanding of conflict that is inter-subjectively validated (or at least not contradicted) when disagreements are made explicit, that justifies our attempt at cross-fertilization. When people disagree, they disagree in the same way and have a shared understanding of what it means to defend their claim, attack the claim of the other, respond to an attack, check a fact or accept a value. This shared conception of conflict should be enough to allow the interaction between political studies and innovation studies but the dangers of misapplying (concepts, insights, theories, etc.) remains real. A full discussion of this issue must await future research, but making the risk explicit is indeed the first step towards avoiding surprises.

A second danger, related to the first one, is that our agonistic proposal threatens to be a mere replacement of one set of implicit standards (conflict is bad, learning is good, etc.) with a new set of implicit standards (conflict is good, learning is not sufficient, responsiveness is bad). In a purely pluralistic fashion we embrace this 'danger' fully. We see this approach as complementary to the other too and not a replacement of them. As a matter of course, we ourselves more often apply the known injunctions of the conciliatory and the constructive approaches: resolve conflict, keep it polite, learn from each other etc. But as we explained, the kind of

\footnotetext{
${ }^{5}$ We thank one anonymous reviewer for pointing out these two dangers.
} 
responsiveness we are after, the one that re-orients the identity of the responsive agent, in short, the kind of agonistic pluralism Mouffe advocates, seems to be precluded by the first two. This is where our agonistic approach can be employed.

\section{Conclusion}

In this paper, we have made a case for an agonistic approach to conflict in innovation. Next the known approaches labelled as conciliatory and constructive, we introduced the agonistic approach to conflicts between stakeholders in the context of responsible innovation. Borrowing insights from agonistic democratic theory, we have theorized and illustrated an approach to conflict from which the risks posed by traditional approaches can be brought to surface and mitigated. The conciliatory approach, with its inclination towards resolution through convincing, is prone to immunization strategies that are meant to resolve the discussion in favour of one of the dominant stakeholders. The constructive approach, while more open in its view of conflict and welcoming of dissent, is prone to standstills or what we have called 'agree-to-disagree' situations. Table 1 below summarizes the differences between the three approaches.

The agonistic approach is a way of tackling risks involved in other approaches. Against immunization, the vulnerability proposed by the agonistic approach promotes the revealing of weak spots through sustained dialogue. Instead of knockdown arguments and 'no-brainers', agonism proposes to embrace the complete lack of certainty whenever complex problems are tackled. This 'dissolution of the landmarks of certainty', to use Claude Lefort's famous phrase, results in a shared and assumed vulnerability among the interacting adversaries. The game is not hopeless for any of the adversaries for each has their vulnerability. Against standstills, the agonistic approach proposes contestation which boils down to a revitalization of a discussion that is made to seem closed. Contestation however is much more than continuing to mumble après le guerre regardless of the arguments one has at one's disposal. As we have seen in the examples above, agonism does not mean refusing to accept a solution you cannot contest but rather continuing to voice

Table 1 The three approaches to conflict in innovation summarized

\begin{tabular}{|c|c|c|c|}
\hline & Conciliatory approach & Constructive approach & Agonistic approach \\
\hline Process & $\begin{array}{l}\text { Convincing/settling - deciding } \\
\text { based on norms of reason- } \\
\text { ableness }\end{array}$ & $\begin{array}{l}\text { Learning about other } \\
\text { standpoints based on } \\
\text { interaction among } \\
\text { stakeholders }\end{array}$ & $\begin{array}{l}\text { Agonistic respect for adversaries } \\
\text { and ethical response to their } \\
\text { demands }\end{array}$ \\
\hline $\begin{array}{c}\text { Prototypical } \\
\text { scenario }\end{array}$ & $\begin{array}{l}\text { The party with the unreasonable } \\
\text { demand retracts their demand } \\
\text { based on rational arguments. } \\
\text { The better argument wins. }\end{array}$ & $\begin{array}{l}\text { The parties truly } \\
\text { understand } \\
\text { alternative } \\
\text { perspectives on the } \\
\text { matter. }\end{array}$ & $\begin{array}{l}\text { The parties discover blind spots in } \\
\text { their perspective and translate } \\
\text { ethical demands into a changed } \\
\text { attitude or actual behaviour. }\end{array}$ \\
\hline Risk & Immunization & $\begin{array}{l}\text { Standstill ('agree to } \\
\text { disagree') }\end{array}$ & Antagonism \\
\hline
\end{tabular}


critique and to problematize if such a solution has not been offered. These two solutions, vulnerability and contestation, need to be applied with an eye for the risk of agonism which is antagonism.

Open Access This article is licensed under a Creative Commons Attribution 4.0 International License, which permits use, sharing, adaptation, distribution and reproduction in any medium or format, as long as you give appropriate credit to the original author(s) and the source, provide a link to the Creative Commons licence, and indicate if changes were made. The images or other third party material in this article are included in the article's Creative Commons licence, unless indicated otherwise in a credit line to the material. If material is not included in the article's Creative Commons licence and your intended use is not permitted by statutory regulation or exceeds the permitted use, you will need to obtain permission directly from the copyright holder. To view a copy of this licence, visit http://creativecommons.org/licenses/by/4.0/.

\section{References}

Avgar, A.C.. (2016) Treating conflict: The adoption of a conflict management system in a hospital setting. Managing and Resolving Workplace Conflict. Emerald Group Publishing Limited, 211-246.

Balliet, D., \& Van Lange, P. A. (2013). Trust, conflict, and cooperation: A meta-analysis. Psychological Bulletin, 139, 1090.

Bercovitch, J., Kremenyuk, V. and Zartman, I.W. (2008) The SAGE handbook of conflict resolution: Sage.

Blok, V. (2014). The Metaphysics of Collaboration: Identity, Unity and Difference in Cross-sector Partnerships for Sustainable Development. Philosophy of Management, 13(2), 53-74.

Blok, V. (2019). From participation to interruption: Toward an ethic of stakeholder engagement, participation, and partnership in corporate social responsibility and responsible innovation. In R. von Schomberg \& J. Hankins (Eds.), International handbook of responsible innovation (pp. 243-259). Celtenham: Edward Elgar.

Blok, V., \& Lemmens, P. (2015). The emerging concept of responsible innovation. Three reasons why it is questionable and calls for a radical transformation of the concept of innovation. In B.-J. Koops, I. Oosterlaken, H. Romijn, et al. (Eds.), Responsible innovation 2: Concepts, approaches, and applications (pp. 19-35). Cham: Springer International Publishing.

Bockris, J., \& Appleby, A. J. (1972). The hydrogen economy - an ultimate economy. Environ This Month, 1, 29-35.

Brand T, Blok V and Verweij M. (2020) Stakeholder dialogue as agonistic deliberation: Exploring the role of conflict and self-interest in business-NGO interaction. Business Ethics Quarterly, 1-28.

Carmo, M., Fritz, D. L., Mergel, J., et al. (2013). A comprehensive review on PEM water electrolysis. International Journal of Hydrogen Energy, 38, 4901-4934.

Collins, L. (2020) Governments are being 'sold a pup on blue hydrogen from methane'. Recharge. United Kingdom: NHST Media Group.

Cuppen, E. (2012). Diversity and constructive conflict in stakeholder dialogue: Considerations for design and methods. Policy Sciences, 45, 23-46.

Cuppen, E., Pesch, U., Remmerswaal, S., et al. (2019). Normative diversity, conflict and transition: Shale gas in the Netherlands. Technological Forecasting and Social Change, 145, 165-175.

De Dreu, C. K. (2008). The virtue and vice of workplace conflict: Food for (pessimistic) thought. Journal of Organizational Behavior, 29, 5-18.

De Levie, R. (1999). The electrolysis of water. Journal of Electroanalytical Chemistry, 476, 92-93.

Den Brink (2020). Duurzame en fossiele waterstof in alle kleuren van de regenboog. https://www. wattisduurzaam.nl/17586/featured/duurzame-en-fossiele-waterstof-in-alle-kleuren-van-de-regenboog/. Accessed Sep 2020.

Deutsch, M. (1994). Constructive conflict resolution: Principles, training, and research. Journal of Social Issues, 50, 13-32.

Deutsch, M., Coleman, P.T. and Marcus, E.C.. (2011) The handbook of conflict resolution: Theory and practice: John Wiley \& Sons.

Dignum, M., Correljé, A., Cuppen, E., et al. (2016). Contested technologies and design for values: The case of shale gas. Science and Engineering Ethics, 22, 1171-1191. 
Elgoibar, P., Munduate, L., \& Euwema, M. (2016). Building trust and constructive conflict management in organizations. In P. Elgoibar, L. Munduate, \& M. Euwema (Eds.), Building trust and constructive conflict management in organizations. Switzerland: Springer.

Erman, E. (2009). What is wrong with agonistic pluralism? Reflections on conflict in democratic theory. Philosophy \& Social Criticism, 35, 1039-1062.

Frey, C. B. (2019). The technology trap: Capital, labor, and power in the age of automation. Princeton: Princeton University Press.

Friedman, B. (1997). Human values and the design of computer technology. Stanford: CSLI Publications; Cambridge University Press.

Gasterra. (2019) Green hydrogen is far too expensive for the moment.

Gasunie. (2020) Europe's largest green hydrogen project starts in Groningen. Available at: https://www. gasunie.nl/en/news/europes-largest-green-hydrogen-project-starts-in-groningen. Accessed Sep 2020

Geijp, J. (2020) Het belang van de brief van Wiebes. Dagblad Noorden.

Glorioso, L. (2015). Cyber conflicts: Addressing the regulatory gap. Philosophy \& Technology, 28, 333-338.

H2Future. (2020) Production of green hydrogen. Available at: https:/www.h2future-project.eu/technology. Accessed Sep 2020.

H-Vision (2019). Blue hydrogen as accelerator and pioneer for energy transition in the industry. https://www. deltalinqs.nl/document/h-vision-final-report-blue-hydrogen-as-accelerator. Accessed Sep 2020.

Hansson, S. O. (2017). The ethics of technology : methods and approaches. London, New York: Rowman \& Littlefield International.

Hård, M. (1993). Beyond harmony and consensus: A social conflict approach to technology. Science, Technology \& Human Values, 18, 408-432.

Hers S, Scholten T, van der Veen R, et al. (2018) Waterstofroutes Nederland.

Hoffmann, P. (2012). Tomorrow's energy: Hydrogen, fuel cells, and the prospects for a cleaner planet. Cambridge, Mass: MIT Press.

IEA. (2019) The future of hydrogen. https://www.iea.org/reports/the-future-of-hydrogen. Accessed 1 Sep 2020.

International Energy Association. (2020) The future of hydrogen.

Irwin, A., Jensen, T. E., \& Jones, K. E. (2012). The good, the bad and the perfect: Criticizing engagement practice. Social Studies of Science, 43, 118-135.

Jasanoff, S. (2007). Technologies of humility. Nature, 450, 33-33.

Jehn, K.A., Rispens, S. and Thatcher Sherry, M.B.. (2012) Managing conflict in groups and teams: Conflict about conflict. In: Margaret AN and Elizabeth AM (eds) Looking Back, Moving Forward: A Review of Group and Team-Based Research. Emerald Group Publishing Limited, 133-159.

Jeong, H.-W. (2009). Conflict management and resolution: An introduction. New York: Routledge.

Jones, R. A. (2019). Concerning the apperception of robot-assisted childcare. Philosophy \& Technology, 32, $445-456$.

Kreuter, W., \& Hofmann, H. (1998). Electrolysis: The important energy transformer in a world of sustainable energy. International Journal of Hydrogen Energy, 23, 661-666.

L'Orange Seigo, S., Dohle, S., \& Siegrist, M. (2014). Public perception of carbon capture and storage (CCS): A review. Renewable and Sustainable Energy Reviews, 38, 848-863.

Le Ber, M. J., \& Branzei, O. (2010). Value frame fusion in cross sector interactions. Journal of Business Ethics, 94, 163-195.

LeValley, T. L., Richard, A. R., \& Fan, M. (2014). The progress in water gas shift and steam reforming hydrogen production technologies - A review. International Journal of Hydrogen Energy, 39, 1698317000.

Ligtvoet, A., Cuppen, E., Di Ruggero, O., et al. (2016). New future perspectives through constructive conflict: Exploring the future of gas in the Netherlands. Futures, 78, 19-33.

Markusson, N., Shackley, S., \& Evar, B. (2012). The social dynamics of carbon capture and storage : understanding CCS representations, governance and innovation. Abingdon: Earthscan.

Mouffe, C. (1999) Deliberative democracy or agonistic pluralism? Social Research: 745-758.

Mouffe, C. (2000). The democratic paradox. London, New York: Verso.

Mouffe, C. (2005). The return of the political. London; New York: Verso.

Northern Netherlands Innovation Board (2018) The green hydrogen economy. Northern Netherlands Innovation Board.

Oakeshott, M. (1990). On human conduct. Oxford: Clarendon Press.

Owen, R., Macnaghten, P., \& Stilgoe, J. (2012). Responsible research and innovation: From science in society to science for society, with society. Science and Public Policy, 39, 751-760. 
Owen, R., Stilgoe, J., Macnaghten, P., et al. (2013). A framework for responsible innovation. In R. Owen, J. Bessant, \& M. Heintz (Eds.), Responsible Innovation (pp. 27-51). London: John Wiley \& Sons, Ltd..

Partington, J. R., \& McKie, D. (1939). Historical studies on the phlogiston theory.-IV. Last phases of the theory. Annals of Science, 4, 113-149.

Paxton, M. (2020). Agonistic democracy: rethinking political institutions in pluralist times. New York: Routledge.

Poel, I. V. D., Royakkers, L., \& Zwart, D. (2015). Moral responsibility and the problem of many hands. New York: Routledge.

Poitras, J., \& Le Tareau, A. (2008). Dispute resolution patterns and organizational dispute states. International Journal of Conflict Management, 19, 72-87.

Putnam, L. (1994). Productive conflict: Negotiation as implicit coordination. International Journal of Conflict Management, 5, 284-298.

Radowitz, B. (2020) Merkel cabinet split on green vs blue hydrogen dilemma. Recharge.

Rey, A.-L. (2017). Agonistic and epistemic pluralisms: A new interpretation of the dispute between Emilie du Châtelet and Dortous de Mairan. Paragraph, 40, 43-60.

Sandole, D.J., Byrne, S., Sandole-Staroste, I., et al. (2008) Handbook of conflict analysis and resolution: Routledge.

Selin, C., Rawlings, K. C., de Ridder-Vignone, K., et al. (2017). Experiments in engagement: Designing public engagement with science and technology for capacity building. Public Understanding of Science, 26, 634-649.

Snelders, H. A. M. (1979). The Amsterdam experiment on the analysis and synthesis of water (1789). Ambix, $26,116-133$.

Stilgoe, J., Lock, S. J., \& Wilsdon, J. (2014). Why should we promote public engagement with science? Public Understanding of Science, 23, 4-15.

Stilgoe, J., Owen, R. and Macnaghten, P.. (2013) Developing a framework for responsible innovation. 42, $1568-1580$.

Swierstra, T., \& Rip, A. (2007). Nano-ethics as NEST-ethics: Patterns of moral argumentation about new and emerging science and technology. NanoEthics, 1, 3-20.

Thornton, P. H., Ocasio, W., \& Lounsbury, M. (2012). The institutional logics perspective : A new approach to culture, structure, and process. Oxford: Oxford University Press.

TKI Nieuw Gas. (2020) Waterstof voor de energie transitie [Hydrogen for the energy transition]. https://www. topsectorenergie.nl/sites/default/files/uploads/TKI\%20Gas/publicaties/Waterstof\%20voor\%20de\% 20energietransitie\%20-\%20innovatieroadmap\%20(jan\%202020).pdf. Accessed 1 Sep 2020.

van de Kerkhof, M. (2006). Making a difference: On the constraints of consensus building and the relevance of deliberation in stakeholder dialogues. Policy Sciences, 39, 279-299.

van den Hoven, J., Doorn, N., Swierstra, T., et al. (2014). Responsible innovation 1: Innnovative solutions for global issues (p. 407). New York London: Springer Science+Business Media Dordrecht.

van Eemeren, F. H. (2010). Strategic maneuvering in argumentative discourse : extending the pragmadialectical theory of argumentation, Amsterdam. Philadelphia: John Benjamins Pub.

Verne, J. (1875). The mysterious island. New York,, Scribner, Armstrong \& co.

Wall Jr., J. A., \& Callister, R. R. (1995). Conflict and its management. Journal of Management, 21, 515-558.

Wennersten, R., Sun, Q., \& Li, H. (2015). The future potential for carbon capture and storage in climate change mitigation-an overview from perspectives of technology, economy and risk. Journal of Cleaner Production, 103, 724-736.

Publisher's Note Springer Nature remains neutral with regard to jurisdictional claims in published maps and institutional affiliations. 